\title{
Prevalence and Practice of Self-Medication among Female
}

\author{
Jesusa V. Gutierrez, Phd RN \\ Rawan Al-Balawi, $R N$ \\ Ghadah Al-Anazi, RN \\ Bashayer Al-Rashidi, RN \\ Manal Al-Homaidi, RN \\ Shemah Al-Atawi, $R N$ \\ Maryam Al-Harfy, $R N$
}

Nursing Students in University of Tabuk, Saudi Arabia

Doi:10.19044/esj.2020.v16n18p273 URL:http://dx.doi.org/10.19044/esj.2020.v16n18p273

\begin{abstract}
Background: Self-medication is a prevalent practice among undergraduate nursing students in Saudi Arabia. This undertakes a great significance among nursing students as they are going to be future healthcare practitioners. Purpose: To determine the prevalence and practices of selfmedication among the female nursing students of the University of Tabuk. Methods: A cross-sectional descriptive design using a pre-constructed questionnaire. The respondents were 128 currently enrolled female nursing students through census sampling. Ethical considerations were done in the conduct of the study. Results: The findings revealed a high prevalence of selfmedication with $79.7 \%$. Most of the respondents were 19 years old $(27.3 \%)$, second and the fourth year, $66(51.6 \%)$ with family income of $>8000$ SAR per month, $84(65.6 \%)$. Top reason for self-medication is to save time (51\%) for the top three upper body diseases such as headache (76.6\%), runny nose (37.3\%) and dental pain (37.3\%); for body diseases were nausea (16.7\%) and fever $(16.7 \%)$ and for Lower body diseases were wounds $(25.5 \%)$. The commonly used medicines were Analgesic (90.2\%), skin ointment (40.2\%), cough syrup (23.5\%) and the traditional medicines (62\%). Brands selection depended on old prescription (37.3\%). The main factor for the selection of the drug was the type of traditional $(60.8 \%)$ due to price and pharmaceutical company. Such medicines for self-medication were obtained from pharmacy shop $89(87.3 .5 \%)$ where half $(51 \%)$ of the respondents read prescription information before self-medicating. Finally, no association was found between the profile and prevalence of self-medication. Self-care is necessary but must
\end{abstract}


be carried out in a safe and responsible actions of self-medicating. Recommendation: The Saudi government must bolster its laws and policies governing Food and drug administration. Though the participants are nursing students, they must be educated with a great emphasis on safe medications and be aware of the side effects, especially those who are not taking pharmacology subject yet as part of the Nursing course.

Keywords: Self-medication, Practice, Self-care, Nursing students

\section{Introduction}

Self-medication is the use of medications without prior medical consultation regarding indication, dosage, and duration of treatment. There are two classifications of drug, prescription only medication, and non-perception medication. Self-medication with OTC medications is called responsible selfmedication, and is an acceptable practice worldwide, whereas buying prescription medications without a prescription from a physician is dangerous and considered as unsafe self-medication (WHO, 1998). Over the counter (OTC) medications can be defined according to the US Food and Drug Authority as "drugs that are safe and effective for use by the general public without seeking treatment by a health professional (USFDA, 2015).

Studies revealed that the increase in self-medication was due socioeconomic factors, lifestyle, ready access to drugs, and the increased potential to manage certain illnesses through self-care and greater availability of medicinal products (WHO, 1998).

Self-medication is a problem that exits world-wide. About $47.6 \%$ prevalence of self-medication has been reported in 2011 (WHO, 1998). In Riyadh $48.8 \%$ of the medications that they use should be dispensed by prescription (Aljadhey, Assiri, Mahmoud et.al, 2015). Studies showed that there are common medications that people usually used for self-medications such as, Nonsteroidal anti-inflammatory drugs (NSAIDs) such as Ibuprofen and Naproxen, Acetaminophen for pain, Chlorpheniramine, Loratadine are for allergy, Decongestants like Pseudoephedrine, phenylephrine, Oxymetazoline (familydoctor.org, 2015). All these medicines have side effects such as dizziness, GI disorder, headache, skin rash, insomnia, and some time it can have a serious side effects like severe allergic reaction (anaphylaxis), liver or kidney damage, bleeding (Gupta, 2018).

Several studies on self-medication practices were done in different countries around the globe and to name a few were Ethiopia, Nigeria, India, Japan, Bangladesh, Saudi Arabia, United States, Canada, Pakistan, Egypt and Slovenia. These countries reported an increase prevalence of self-medication practices. 
In Mansoura University, Egypt $62.9 \%$ of students are practicing selfmedication (Helal \& Abou-ElWafa, 2017). In King Saud University, Saudi Arabia, undergraduate medical and non-medical, results showed that there was $50.9 \%$ are practicing self-medication (AlRaddadi, Barakeh, AlRefaie, et.al, 2017). In Mafraq Governorate, Jordan, study showed that the prevalence of self-medication among school students was generally high $87.0 \%$ (Albashtawy, Batiha, Monim et al, 2014).

In Gondar University, Ethiopia on Health Sciences Students (414) $38.5 \%$ of the students had practiced self-medication. In Ayder campus of Mekelle University, Ethiopia, 55.6\% from 1218 students self-medicate. (Abay \& Amelo, 2010). 104 (36.70\%) agreed with the practice of self-medication while 148 (52.30\%) disagreed (Gutema, Gadisa \& Kidanemariam, 2011).

In Southwestern Nigeria that $91.4 \%$ of the participants are practicing self-medication with antibiotics and anti-malarial drugs, while the $8.7 \%$ stated that they were not. An association yielded between the age group and the practice of self-medication. On the other hand, self-medication practice is very common among the middle age groups of 25 - 34 and 35 - 44 years (Osemene \& Lamikanra, 2012). In South India, from 440 medical students, 78.6\% practice self-medication and a larger number were female. Antipyretics were most commonly used with $74.8 \%$ (Kumar, Kanchan \& Unnikrishnan, 2013). In Ohasama Japan, from 1008 participants, 519 (52\%) participants used OTC medications or dietary supplements which predicted an increased selfmedication practice in rural areas (Satoh, Matsumoto \& Hara, 2014).

In Bangladesh, from a total of 250 participants, $88.0 \%$ are practicing self-medication which is an alarming public health issue and the practice might increase (Seam, Bhatta \& Saha, 2018). In Valsad Gujarat, 234 undergraduate medical students practiced self-medication as well. (Shah, Patel, Nayak, 2018). In Ljubljana university, Ljubljana, Slovenia, the prevalence of self-medication was 1,195(92.3\%) between 1,294 students from the healthcare and non-healthcare student taking medications without consulting a doctor (Limaye, Fortwengel \& Limaye, 2017). In United States and Canada, 125 (69.1\%) undergraduate medical students of the students practice self-medication, and the knowledge, perception and total scores were 73.45, 62.75 and 136.2 (Shankar, Ravi \& Dubey et.al, 2016)

In Bhopal, Madhya Pradesh, out of 139 students, a total 123 (88.5\%) students Self-medicated and the rest $16(11.5 \%)$ have not taken Selfmedication. Most common reasons for taking Self-medication were that there was no need to visit the doctor for minor illness (71\%), it was time saving $(58 \%)$, self-medication provided quick relief $(55 \%)$ and there was ease and convenience in taking Self-medication (44\%). The source of information of the drugs used for self-medication was previous prescription, 97 (70\%), medical store, 78 (565). Out of total 139, 109 (78\%) Self-medicated for 
headache followed by cough and cold, 98 (70\%) and fever, 90 (65\%) (Sankdia, Agrawal, Rekha et.al, 2017).

In Ain Shams University, Egypt, 300 near coming physicians revealed that self-medication was $55 \%$. 58.8\% took antibiotics, $54.4 \%$ took vitamins, $87.2 \%$ took analgesics, $12 \%$ took tranquilizers, and $28 \%$ took herbal products without a prescription. $14.4 \%$ follow prescriptions correctly. A prescription compared to $63.3 \%$ has always stopped taking the drug to improve the feeling, and $13.6 \%$ always repeat the prescription without seeking medical advice. Also $60 \%$ said they have increased dosage without medical consultation. The side effects reported $4.8 \%, 1.6 \%$, and $12 \%$ as a result interaction of drugs, increased dose without medical consultation and early cessation of treatment respectively (El Ezz \& El-arab, 2011).

Commonly used medications are antibiotic (58.8\%), vitamins (54.4\%), analgesics $(87.2 \%)$, sedatives $(12 \%)$ and herbal products $(28 \%)$, (Ez-Elarab 2011); antibiotics (53.8\%) anti-malarial (46.3\%), (Osemene \& Lamikanra, 2012); antipyretics (83.06\%), (Shah, Patel, Nayak, et.al, 2018); antibiotics (63.91\%), (Patil, Vardhamane, Santoshkumar et. al, 2014); antipyretics (74.8\%), (Kumar, Kanchan, Unnikrishnan et.a al., 2013) headache (72.4\%), (Zafar, Syed, Waqar, et.al, 2008) and antipyretics (58.40\%), (Seam, Bhatta, Saha, et.al., 2018).

In relation to year level of students, more healthcare students in their senior year $(94.1 \%)$ than those in their junior year $(89.4 \%)$ practiced selfmedication (Klemenc-Ketis, Hladnik \& Kersnik, 2010). 47\% of the participants opined that self-,medication was a part of self-care and it needs to be encouraged (Kumar, Kanchan, Unnikrishnan et.a al., 2013). Selfmedication was significantly associated with age, gender and student's class level in the University of Southwestern Nigeria at $\mathrm{p}<0.0001$. Among undergraduates, self-medication increased as the students' class level in the university increased (Osemene \& Lamikanra, 2012). A significant $(\mathrm{p}<0.05)$ portion of the students ( $51 \%$ male and $43 \%$ female) perceived it was acceptable practice as they considered self-medication to be as segment of self-care.

Considering all these evidences, no study has been widely done in Tabuk, Saudia Arabia regarding this topic, and mostly participants in different countries involve other healthcare students without nursing students. Practices in self-medication remain an issue of intense in academic discourse. Practices in self-medication have raised a lot of questions in the mind of the researchers. Hence, this research work focuses on assessing the practices about selfmedication among the nursing students of University of Tabuk. The study compares the age and year level with the extent of practices on selfmedication. 


\section{Materials \& Methods \\ Research Design}

In this study, a university-based cross-sectional descriptive study was employed. Descriptive research aimed at casting light on current issues and problems through a process of data collection for the description of the situation. It is also known as a statistical research, it describes data and characteristics about the population or phenomenon being studied (Calderon, 2008). Descriptive research primarily focuses on describing the nature of a demographic segment, without focusing on "why" a certain phenomenon occurs. In other words, it "describes" the subject of the research, without covering "why" it happens (Bhat, 2019). In this study the demographic profile of the respondents was described. A correlational research design was also employed to determine relationships between variables (Schober, Boer \& Schwarte, 2018).

\section{Sampling and Setting}

Census sampling was used in choosing the respondents because all members of the female nursing population were studied (Lavrakas, 2008). The target population were the $100 \%$ enrolled female nursing students of the University of Tabuk, Tabuk City, and Kingdom of Saudi Arabia. There were 146 students. Freshmen, 34 (23.3\%), Second year, 37 (25.3\%), Third year, 41 (28.1\%) and the Fourth year students, 34 (23.3\%) respectively. Study was done from February to May, 2018.

\section{Research Instrument}

The researchers used a standardized questionnaire as the main tool in data gathering. The standardized questionnaire was obtained from WHO entitled "Self-medication study questionnaire". The questionnaire was divided in two sections: Section A comprised of the demographic data: the age, academic year and socioeconomic status of the respondents and Section B comprises of 8 items questions based on the purpose of the research work. Section B of the questionnaires answers the questions on the practices of self-medication regarding the main reason for self-medication, the main medical condition (diseases) for self-medication, drugs commonly used for self-medication, the factors considered in selecting the drug for selfmedication, selection of specific brand for self-medication, place where drugs are obtaining for self-medication and checking the prescribing information before self-medication or not. For those who did not self-medicate they did not continue on answering remaining 7 questions. For those who selfmedicated, they answered questions 1-8. Every question is answerable by Yes or No. For those who selected Brand in question \#5 which is factor considered in selecting drug for self-medication, they continued answering number 9 
which is the place where the drug is obtained and 10 if they check the prescribing information before self-medicating.

\section{Data Gathering}

A letter of permission to conduct the study was prepared by the researchers which was noted by the recommending approval of the Supervisor of the Nursing Department, Tabuk University. The letter was forwarded to the Nursing Department Head to seek permission to conduct the research study for Ethical approval. After administrative clearance and ethical approval to conduct the study was secured, questionnaires were distributed to the nursing students at all year levels. The researchers made sure they are present on the appointment day of the floating of the questionnaires to the respondents of the study for easy access on any clarifications or queries that may be raised. The data collectors gave a brief introduction to the respondents by explaining the aims and purpose of the study and a written consent was obtained from all the respondents, the first to fourth year female nursing students.

\section{Analysis}

The data gathered were subjected to statistical treatment in order to answer the specific problems in the study. Answers from the respondents were coded, tallied and analyzed using Statistical package for the Social Sciences (SPSS) Version 21. The statistical treatment used in this study includes a descriptive and inferential statistics which answered the four stated problems: Frequency and Percentage in order to analyze the demographic profile data of the respondents. It was also utilized in analyzing the data of prevalence of self-medication. Chi-Square Independence Test is a procedure for testing if two categorical variables are related in some population. In this study, it is employed to see if there was a relationship between the first variable, the demographic profile; and the second variable, the prevalence of self-medication.

\section{Results}

Among the 128 respondents, 35 or $27.3 \%$ were 19 years old , 25\% were 21 year old, $21.1 \%$ were 20 years old, $20.3 \%$ were 22 years old, $5.5 \%$ were 23 years old and only $0.8 \%$ or 1 among the respondents was a 25 year old. There was almost the same representation of the respondents in terms of their year level. The second and fourth year had the same population of 33 students each while the first and third year were also with the same number of 31 students. For the socio-economic status of the respondents, most of the respondents had their monthly income of $>8000$ represented by $84(65.7 \%)$ followed by $16.4 \%$ of those on the bracket $3000-5000$, followed by $13.3 \%$ for those with socio-economic status bracket of $6000-8000$ while only $3.9 \%$ have 
$<3000$ income per month (Table 1). There was a high prevalence of selfmedication among the nursing students of the University of Tabuk. It is alarming to note that $79.7 \%$ of the respondents were engaged with selfmedication practices. There were several reasons why the respondents selfmedicated (Table 2).

The most reported reason for self-medication was to save time coming from $52(40.6 \%)$ respondents, second was having an old prescription, followed by a pharmacist advice and having medicines available from family members and the least reported reason is no trust in doctors $1(0.8 \%)$ respondent (Table 3 ). The respondents of this study self-medicated primary for the diseases affecting the upper body such as headache $72(70.6 \%)$ which was reported as rank 1 among the listed upper body diseases, followed by dental pain and runny rose of same frequency and percentage, 38 (37.3\%), and the least reported diseases were faint and epilepsy $1(1.0 \%)$. For the diseases effecting the body, the highest reported diseases were nausea and fever 17 (16.7\%). For the lower body the highest reported disease was wounds 26 (25.5\%), followed by muscle pain and menstrual problems 23 (22.5\%) (Table 4). Drug requested for self-medication used among the respondents were analgesic with $92(90.2 \%)$ was the highest reported among the drug categories, followed by skin ointment $41(40.2 \%)$ and Antidiarrheal with 5 (4.9\%) was the least reported (Table 5). The highest factor the respondents considered while selecting the drugs for self-medication were the type of drugs that are traditional $62(60.8 \%)$ while the price $6(5.9 \%)$ was the least (Table $\underline{6}$ ). The respondents who selected brand for self-medication were further asked what their criteria for selection of particular brand is. They reported that old prescription of doctor 38 (29.7\%) was the highest (Table 7). Respondents obtained drugs for self-medication. The highest reported was pharmacy shop $89(87.3 \%)$ followed by the previous experience 23 (22.5\%) (Table 8 ). Half of the respondents were checking the prescribing information before selfmedicating with $52(51.0 \%)$ while it is alarming to note also that $42(41.2 \%)$ were reading prescription for sometimes and $8(7.8 \%)$ never read at all (Table 9).

Table 1 Demographic profile

\begin{tabular}{cccc}
\hline Variables & & $\mathrm{N}$ & $\%$ \\
\hline Age & 19 & 35 & 27.3 \\
& 20 & 27 & 21.1 \\
& 21 & 32 & 25.0 \\
& 22 & 26 & 20.3 \\
& 23 & 7 & 5.5 \\
& 25 & 1 & .8 \\
Year & Total & 128 & 100.0 \\
Level & First year & 31 & \\
& & &
\end{tabular}




\begin{tabular}{cccc} 
& Second year & 33 & 25.8 \\
& Third year & 31 & 24.2 \\
& Fourth year & 33 & 25.8 \\
Total & 128 & 100.0 \\
Socio- & $<3000$ & & \\
economic & & 5 & 3.9 \\
Status & & 21 & \\
& $3000-5000$ & 17 & 16.4 \\
& $6000-8000$ & 84 & 13.3 \\
& $>8000$ & 128 & 65.6 \\
& Total & & \\
\hline
\end{tabular}

Table 2. Prevalence of Self-Medication

\begin{tabular}{ccc}
\hline Practicing Self-Medication & $\mathrm{N}$ & $\%$ \\
\hline No & 26 & 20.3 \\
Yes & 102 & 79.7 \\
Total & 128 & 100.0 \\
\hline
\end{tabular}

Table 3. Reason for Self-Medication

\begin{tabular}{ccc}
\hline Reason & $\mathrm{N}$ & $\%$ \\
\hline Doctor / clinic far from home & 11 & 10.8 \\
High fees of doctor & 3 & 2.9 \\
Doctor is busy with many patients & 6 & 5.9 \\
No trust in doctor & 1 & 1.0 \\
Saves time & 52 & 51.0 \\
I have old prescription & 35 & 34.3 \\
I have medicines of family members & 22 & 21.6 \\
Pharmacist advice & 33 & 32.4 \\
Other. Explain & 15 & 14.7 \\
\hline
\end{tabular}

Table 4. Diseases for self-medication in last 3 months

\begin{tabular}{ccc}
\hline Upper Body Disease & $\mathrm{N}$ & $\%$ \\
\hline Headache & 72 & 70.6 \\
Dandruff & 7 & 6.9 \\
Hair fall & 22 & 21.6 \\
Faints & 1 & 1.0 \\
Epilepsy & 1 & 1.0 \\
Migraine & 8 & 7.8 \\
Other. Specify & 2 & 2.0 \\
Eye infection & 8 & 7.8 \\
Running nose & 38 & 37.3 \\
Ear pain & 13 & 12.7 \\
Mouth ulcer & 4 & 3.9 \\
Dental pain & 38 & 37.3 \\
Cough & 29 & 28.4 \\
\hline Body Disease & Frequency & Percent \\
Difficulty in swallowing & 9 & 8.8 \\
Acidity & 12 & 11.8 \\
Vomiting & 8 & 7.8
\end{tabular}




\begin{tabular}{ccc} 
Nausea & 17 & 16.7 \\
Asthma & 10 & 9.8 \\
Diarrhea & 7 & 6.9 \\
Body pain. Specify & 9 & 8.8 \\
Other. Specify & 2 & 2.0 \\
Dysentery & 11 & 10.8 \\
Rash & 2 & 2.0 \\
Fever & 17 & 16.7 \\
Skin disease on open areas & 9 & 8.8 \\
Diabetes & 2 & 2.0 \\
Hypertension & 2 & 2.0 \\
\hline Lower Body Disease & Frequency & Percent \\
\hline Pain in joints & 14 & 13.7 \\
Arthritis & 5 & 4.9 \\
Muscle pain & 23 & 22.5 \\
Varicose veins & 1 & 1.0 \\
Wounds & 26 & 25.5 \\
Genital infection & 0 & 0.0 \\
Other. Specify & 0 & 0.0 \\
\hline transmitted disease STD & 0 & 0.0 \\
Skin disease in covered areas & 1 & 1.0 \\
Impotency & 0 & 0.0 \\
Urination problems & 1 & 1.0 \\
Menstrual problems & 23 & 22.5 \\
\hline
\end{tabular}

Table 5. Drugs used for self-medication

\begin{tabular}{ccc}
\hline Categories of Drugs & $\mathrm{N}$ & $\%$ \\
\hline Analgesic & 92 & 90.2 \\
Antipyretics & 22 & 21.6 \\
Antacids & 7 & 6.9 \\
Antihistamine & 12 & 11.8 \\
Antidiarrheal & 5 & 4.9 \\
Cough syrup & 24 & 23.5 \\
Nutritional supplements & 37 & 36.3 \\
EyelEar drops & 24 & 23.5 \\
Skin ointment & 41 & 40.2 \\
Others & 0 & 0.0 \\
\hline
\end{tabular}

Table 6. Factors to consider while selecting the drug for self-medication

Factors in Selecting Drug for self-

\begin{tabular}{ccc} 
medication & N & $\%$ \\
\hline Price & 6 & 5.9 \\
Pharmaceutical company & 19 & 18.6 \\
Preventive & 29 & 28.4 \\
Pharmacological & 20 & 19.6 \\
Traditional & 62 & 60.8 \\
Brand & 14 & 13.7 \\
Explain & 15 & 14.7 \\
\hline
\end{tabular}


Table 7. Selection of particular brand

\begin{tabular}{ccc}
\hline Selection of particular brand & $\mathrm{N}$ & $\%$ \\
depends on & 2 & 2.0 \\
Recommended by pharmacist & 37 & 36.3 \\
Used by peers - friends / family & 22 & 21.6 \\
My previous experience & 38 & 37.3 \\
Old prescription of doctor & 16 & 15.7 \\
Advertisement & 7 & 6.9 \\
Other & \\
Table 8. Place where drugs are obtain & $\%$ \\
\hline Place $\quad$ N & 87.3 \\
Pharmacy shop & 89 & 10.8 \\
Primary health care center & 11 & 22.5 \\
My previous experience & 23 & 5.9 \\
Old prescription of doctor & 6 & 2.0 \\
Advertisement & 2 & 1.0 \\
Other & 1 &
\end{tabular}

Table 9. checking the prescription information before self-medication

\begin{tabular}{ccc}
\hline Checking the prescription information & $\mathrm{N}$ & $\%$ \\
\hline Yes, always & 52 & 51.0 \\
Yes, sometimes & 42 & 41.2 \\
No, never & 8 & 7.8 \\
Total & 102 & 100.0
\end{tabular}

Table 10.Table of Significance

\begin{tabular}{|c|c|c|c|c|}
\hline \multirow{2}{*}{$\begin{array}{c}\text { Demographic } \\
\text { Profile }\end{array}$} & \multicolumn{3}{|c|}{ Pearson Chi-Square } & \multirow{2}{*}{$\begin{array}{c}\text { Decision on } \\
\text { Hypothesis }\end{array}$} \\
\hline & Value & df & $\begin{array}{c}\text { Asymp. Sig. (2- } \\
\text { sided) }\end{array}$ & \\
\hline \multirow[t]{3}{*}{ 1. Age } & & 5 & .245 & \multirow{6}{*}{$\begin{array}{l}\text { No significant } \\
\text { relationship } \\
\text { On Age, Year } \\
\text { level and Socio- } \\
\text { economic status }\end{array}$} \\
\hline & $\begin{array}{l}0.089 \mathrm{~d} \\
7842\end{array}$ & 5 & .165 & \\
\hline & $\begin{array}{l}.042 \\
.002\end{array}$ & 1 & .968 & \\
\hline \multirow[t]{3}{*}{ 2. Year level } & $5.829 \mathrm{a}$ & 3 & .120 & \\
\hline & 5.345 & 3 & .148 & \\
\hline & .258 & 1 & .612 & \\
\hline 3. Socio- & $2.032 \mathrm{a}$ & 4 & .730 & $\mathrm{H}_{0}$ \\
\hline economic & 2.080 & 4 & .721 & \\
\hline Status & .001 & 1 & .971 & \\
\hline
\end{tabular}

\section{Discussion}

The result is considered as an alarming public health issue and the practice might increase. Younger students self-medicated more than the older students. The fact that 19 years old students chose drugs for self-medication 
based on their own knowledge and experience, might be due to the fact that they believed they have enough knowledge to self-diagnose and self-medicate without additional examination. This is incongruent with self-medication practice in Southwestern Nigeria which is common among the middle age groups of 25 - 34 and 35 - 44 years (Osemene \& Lamikanra, 2012). On the other hand, this study is similar in Mansoura University, Egypt on selfmedication practices among the students wherein $62.9 \%$ of students are practicing self-medication (Helal \& Abou-ElWafa, 2017). Likewise, in King Saud University, undergraduate medical and non-medical students showed $50.9 \%$ of the respondents self-medicated (Alraddadi \& Barakeh, 2017). Moreover, in Mafraq Governorate, Jordan, study showed that the prevalence of self-medication among school students was generally high 87.0\% (AlBashtawy, Batiha, \& Tawalbeh, 2014).

In this study, most students who self-medicate were second and fourth year college nursing students which is contradicting with the study made in India, more healthcare students who self-medicated were in their senior year (94.1\%) than those in their junior year (89.4\%) (Klemenc-Ketis, Hladnik, Kersnik, 2010). 47\% of the participants opined that self- medication was a part of self-care and it needs to be encouraged, (Kumar, Kanchan, Unnikrishnan et.al, 2013). Different studies have seen link between socio-economic status and self-medication practices. There are factors associated with selfmedication which include socio-economic factor as an important factor (WHO, 1998). Usually developing countries are those who use the drug without prescription with is similar to this study. Also the social and psychological reasons, the educational background of the person and many uses of medication through his personal experiences, and the relative knowledge of medication. Most of the respondents came from a developing country with higher socio-economic status (WHO, 1998). Conversely, the age, year level and socio-economic factors of the nursing participants in the study are not factors to self-medication practice.

Though there may be potential benefits of self-medication, the potential risks cannot be underestimated also. Ordinary person may have knowledge deficient regarding the principals of pharmacology, or the features of the used medication that can result in incorrect self-diagnosis, unsuitable therapy choice, severe side effects, and unable to determine the contraindication, interactions, or precaution. The prevalence of selfmedication is a worldwide problem, about $47.6 \%$ self-medicate (WHO, 1998). The self-medication prevalence around the world cited from different studies is surmounting which confirm the results in this study. It is comparable with the different studies made in Egypt, 62.9\%, Helal \& Abou-ElWafa (2017), Ethiopia, $38.5 \%, 55.6 \%$ agreed about self-medication practice (Abay \& Amelo, 2010), in Mekelle University, Ethiopia, 43.24\%, in 
Southwestern Nigeria, 91.4\% , in South India, 78.6\%, (Kumar, Kanchan, \& Unnikrishnan, et al., 2013), in Japan, 52\% (Satoh, Matsumoto, \& $\underline{\text { Hara, et al., }}$ 2014), in Bangladesh, 88.0\% (Omar, Rita, \& Bijoy et al., 2018), in Kalaburagi, India (54\%), in India, 88.18\%, Shivaraj, Vardhamane, \& Paretil, et al., (2014), $91.50 \%$ of the Medical College students in Valsad Gujarat (Shah, Patel, Nayak, 2018), in Ljubljana, Slovenia, 92.3, (Klemenc-Ketisa \& Janko, 2009), in United States and Canada 69.1\% (Ravi, Arun, \& Neelam et al., 2016), in Madhya Pradesh, 88.5\%, (Sankdia, \& Agrawal, et al., 2017), in Egypt, 55\%. (El-ez, \& Ez-elarab, 2011), in Pakistan, 76\%.

Nursing student's life is pressing and taxing with academic requirements requiring an ample time to be spent on accomplishing such tedious tasks. This owes the students to self-medicate in order to save time instead of going to a pharmacist and seek advice or visit a clinic or hospital when they feel sick. The identified second highest reason which is the old prescription availability is somewhat risky due to the fact that they may have knowledge deficient regarding the principals of pharmacology, or the features of the used medication that can result in incorrect self-diagnosis, unsuitable therapy choice, severe side effects, and unable to determine the contraindication, interactions, or precaution (WHO, 1998). In this study, the highest identified reason for self-medication with $40.6 \%$ is saving time, $34.3 \%$ had old prescription which is inconsistent with a study done where saving time/busy lifestyle was the least Gutema, Gadisa, \& Kidanemariam, (2011) where students of Mekelle University found that old prescription (39.1\%) was the highest reported reason for self-medication which is the second highest reported reason (34.3\%) in this study (Shah, Patel \& Nayak, 2018).

Headache was the number one reported disease (51.56\%) in Ayder campus of Mekelle University, Ethiopia (Gutema, Gadisa, \& Kidanemariam, 2011). Somehow, the result in this study is alarming because the respondents self-medicated for some ailments that require visit to a medical practitioner in a clinic or hospital for diseases like cough, migraine, epilepsy, ear pain, acidity, asthma, dysentery, and the likes. The respondents may have knowledge deficient regarding the principals of pharmacology, or the features of the used medication that can result in incorrect self-diagnosis, unsuitable therapy choice, severe side effects, and unable to determine the contraindication, interactions, or precaution (WHO, 1998).

Students without background with pharmacology need to know that Nonsteroidal anti-inflammatory drugs (NSAIDs) such as Ibuprofen and Naproxen, Acetaminophen for pain, Chlorpheniramine, Loratadine are for allergy, Decongestants like Pseudoephedrine, phenylephrine, Oxymetazoline have side effects such as dizziness, GI disorder, headache, skin rash, insomnia, and some time it can have a serious side effects like severe allergic reaction (anaphylaxis), liver or kidney damage, bleeding (Gupta, 2018). 
The result of this study showed that respondents have high frequency of self-medication with drugs like nutritional supplements, skin ointments, ear drops and the likes. There are side effects reported $4.8 \%, 1.6 \%, 12 \%$ as a result interaction of drugs, increased dose without medical consultation and early cessation of treatment respectively (El-ez, \& Ez-elarab, 2011). In related studies, the commonly used medications were antibiotic (58.8\%), vitamins (54.4\%), analgesics (87.2\%), sedatives (12\%) and herbal products (28\%), (EzEl-arab 2011); otolaryngology problems (22.5\%), (Ali, Ibrahim \& Palaian, 2010); antibiotics (53.8\%) anti-malarial (46.3\%), (Osemene \& Lamikanra, 2012); antipyretics (83.06\%), (Shah, Patel, Nayak, et.al, 2018); hadache/fever (20.7\%) (Mesfin \& Eticha, 2014); antibiotics (63.91\%), (Patil, Vardhamane, Santoshkumar et. al, 2014); antipyretics (74.8\%), (Kumar, Kanchan, Unnikrishnan et.a al., 2013) headache (72.4\%), (Zafar, Syed, Waqar, et.al, 2008) and antipyretics (58.40\%), (Seam, Bhatta, Saha, et.al., 2018); 74.8\% (Kumar, Kanchan, \& Unnikrishnan, et al., (2013). In Japan, 52\% participants used OTC medications or dietary supplements, (Satoh, Matsumoto, \& $\underline{\text { Hara, et }}$ al., 2014).

Among Saudi people, traditional medicine has become popular and they used herbal medicines without prescription or without consulting their healthcare professionals. While the purpose of using traditional medicines is for therapeutic reasons, facilitated perceptions and attitudes of the students, it is important to ensure standardization, stability and quality control of the use of the medicines in Saudi Arabia. When a person felt relief with the previous prescription form the former prescription of doctor, the tendency is to adopt the same practice when the same ailment occurs. Somehow, there are different potential risks for self-medications such as self-diagnosis, administration or dosing. Hence, inappropriate self-medication may harm individuals due to increasing the risk of drug misuse or delaying a hospital visit by masking some symptoms.

Most of the respondents reported that their selection of dugs based on the previous doctor's prescription $(52.8 \%)$ while in related studies, the previous experience was the second highest reported where it is the third reported based in this study (Seam, Bhatta \& Saha, 2018).

Medicines were available and distributed primarily by pharmaceutical companies in different pharmacies or hospitals. However, the availability of information about rational handling and the use of these medicines is inadequate. It is very common among the respondents to obtain their drug for self-medication in the pharmacy shop. The pharmacist need to educate students about the pros and cons of self-medication. The finding were similar to our study, where they found majority of the students obtained drugs used for self-medication from pharmacy (Osemene \& Lamikanra, 2012). Since half of the respondents had their pharmacology course during their third year, 
it can be attributed that somehow they have knowledge on drugs as to its side effects, adverse effects and contraindication. It has to be known that prescription information are designed for the purpose of how to take it safely. Students must not overlook those things because they might taught they are not so important. In other studies, $83.6 \%$ of their respondents checking the package insert before self-medication (Seam, Bhatta \& Saha, 2018).

There was no significant association found between the age, year level and socio-economic status with the prevalence of self-medication practice among nursing students in this study. The findings is not congruent with the study of Osemene \& Lamikanra (2012) whose results revealed that the practice of self-medication was high among the age group of $25-44$ years but lower in the $15-24$ and $\geq 45$ year age groups, respectively. Females exhibited higher prevalence of self-medication than males. Among undergraduates, selfmedication increased as the students' class level in the university increased. Postgraduate students exhibited low prevalence of self-medication practices. Self-medication was significantly associated with age, gender and students' class level in the university at $\mathrm{p}^{\prime}<0.001$.

Self-care is a broad concept which encompasses any action you take for your physical, mental and emotional health. This may include treatment of a minor illness. Self-medication must be carried out in a safe and responsible selection and use by individuals to treat self-recognized illnesses or symptoms. It is important to increase awareness on pharmacology to empower you to practice safe and effective self-care, prepare students with comprehensive lecture on pharmacology in order to have background about drug information, prevent the potential risk of medications and be able to impart knowledge to their patients, family and people in the community regardless of the students' background on medicines. The hospitals should increase the awareness of the community about self-medication through Activities or distribution of posters when each patient receives their medication from the pharmacy. The Saudi Food and Drug Authority (SFDA) should increase control over drugs that have many side effects, so they should be prescribed by prescription to be safe and appropriate for the patient. Lastly, pharmacists should not dispense drugs without explaining their side effects.

\section{Conclusion}

There is high prevalence of self-medication among nursing students in University of Tabuk which is an alarming health concern. Younger students self-medicated more than the older students. Though there may be potential benefits of self-medication, the potential risks cannot be underestimated and these require emphasis especially to the nursing students who haven't taken Pharmacology subject yet. The main reason for self-medicating which is to save time should not excuse their wrong practices. Self-care is necessary but 
must be carried out in a safe and responsible actions of self-medicating. The Saudi government must bolster its laws and policies of Saudi Food and drug Authority and train pharmacist to educate customers on drugs side effects and not to dispense prescription medications without a prescription. Lastly, there must be a massive health education campaign on the safe use of medications.

\section{References:}

1. Abay, S. \& Amelo, W. (2010). Assessment of Self-Medication Practices among Medical, Pharmacy, Health Science Students in Gondar University, Ethiopia. Journal of Young Pharmacist, Volume 2, Issue 3, July-September 2010, Pages 306-310. https://doi.org/10.4103/0975-1483.66798

Ali, S., Ibrahim, M. \& Palaian, S. (2010). Medication storage and selfmedication behavior amongst female students in Malaysia. Pharmacy Practice, 15 Mar 2010, 8(4):226-232 https://doi.org/10.4321/S1886-36552010000400004

2. Aljadhey, H., Assiri, G., Mahmoud, M., Al-Aqeel, S. and Murray, M. (2015). Self-medication in Central Saudi Arabia. Community pharmacy consumers' perspectives. Saudi Medical Journal, 01 Mar 2015, 36(3):328-334 https://doi.org/10.15537/smj.2015.3.10523

3. Al-raddadi, KK, Barakeh, RM, Al-refaie, SM, Al-yahya, LS, Adosary, MA \& Al-yahya KI (2017). Determinants of self-medication among undergraduate students at King Saud University: Knowledge, attitude and practice. Journal of Health Specialties, 2017; 5:95-101 https://doi.org/10.4103/2468-6360.205078

4. Bhat, A. (2019). Descriptive Research: Definition, Characteristics, Methods, Examples and Advantages. QuestionPro https://www.questionpro.com/blog/descriptive-research/

5. El-ez, N. \& Ez-elarab, E. (2011). Knowledge, Attitude and Practice of medical students towards self- medication at Ain Shams University, Egypt. J PREV MED HYG 2011, 52(4); 196-200. https://www.ncbi.nlm.nih.gov/pubmed/22442925

6. Eticha, T. \& Mesfin, K., (2014). Self-medication Practices in Mekelle, Ethiopia. PLOS/ONE, May 2014, volume 9, Issue 5, e97464. https://doi.org/10.1371/journal.pone.0097464

7. Gupta, S. (2018). OTC Drug Dangers You Should Know About.

8. Gutema, G., Gadisa, D., Kidanemariam, Z. and Berhe, D. (2011). SelfMedication Practices among Health Sciences Students: The Case of Mekelle. University. Journal of Applied Pharmaceutical Science 01 (10); 2011: 183-189 http://www.japsonline.com/admin/php/uploads/325_pdf.pdf 
9. Helal,S. \& Abou-ElWafa (2017). Self-Medication in University Students from the City of Mansoura, Egypt. Journal of Environmental and Public Health, Volume 2017. https://doi.org/10.1155/2017/9145193

10. Klemenc-Ketis, Z., Hladnik, Z., \& Kersnik, J. (2010). Self-medication among Non-healthcare Students at University of Ljubljana, Slovenia. Medical Principle and Practice, 2010; 19:395-401 https://doi.org/10.1159/000316380

11. Kumar, N, Kanchan, T., Unnikrishnan, B., Rekha, T., Mithra, P., Kulkarni, V., Papanna, MK, Holla, R. \& Uppal, R. (2013). Perceptions and Practices of Self-medication among Students in Coastal South India. PLOS/ONE, August, 2013, Volume 8, Issue 8/e72247.

https://doi.org/10.1371/journal.pone.0072247

Lavrakas, PJ. (2008). Encyclopedia of Survey Research Methods. https://doi.org/10.4135/9781412963947

12. Osemene \& Lamikanra, (2012). A study of the Prevalence of Selfmedication Practices among University Students in Southwestern Nigeria. Tropical Journal of Pharmaceutical research, August, 2012; 11(4), 683-689. https://doi.org/10.4314/tjpr.v11i4.21

13. Patil S, Vardhamane S. H., Patil B.V., Santoshkumar J, Binjawadgi AS, Kanaki AR ( 2014). Self-Medication Practice and perceptions among Undergraduate Medical Students; A cross- Sectional Study. Journal of Clinical and Diagnostic research, 2014 Dec., Vol 8 (12). https://doi.org/10.7860/JCDR/2014/10579.5313

14. Satoh, M., Matsumoto, A., Hara, A., Iwamori, S., Obara, T., Kikuya, M., Metoki, H., Hosaka, M., Asayama, K., Takahashi, N., Sato, H., Mano, N., Imai, Y. and Ohkubo, T. (2014). A Survey of Selfmedication Practices and Related Factors in the General Population: the Ohasama Study. J-stage. Yakugaku Zasshi, 134(12), 1347-1355. https://doi.org/10.1248/yakushi.14-00179

15. Schober, P, Boer, \& Schwarte (2018). Correlation Coefficients. International Research Anesthesia Society. Anesthesia and Analgesia. May 2018 - Volume 126 - Issue 5 - p 1763-1768 https://doi.org/10.1213/ANE.0000000000002864

16. Seam, OR, Bhatta R, Saha BL , Das A, Hossain M, Uddin S, Karmakar P,Choudhuri SK

17. \& Sattar MM (2018). Assessing the perceptions and Practice of SelfMedication among Bangladehsi Undergraduate Pharmacy Students. MDPI Pharmacy, 2018, 6, 6 https://doi.org/10.3390/pharmacy6010006

18. Shah, H., Patel, R., Nayak, S., Patel HR \& Sharma D. (2018). A questionnaire-based cross sectional study on Self-medication Practices 
among Undergraduate Medical Students of GMERS Medical College, Valsad, Gujarat, India. International Journal of Medical Science and Public Health, 2018, Vol 7, issue 4 https://doi.org/10.5455/ijmsph.2018.0101324012018

19. Sankdia, R., Agrawal, M., Rekha, P. and Kothari, N. (2017). A Questionnaire Based Study Regarding the Knowledge, Attitude and Practice of Self- Medication among Second Year Undergraduate M. International Journal of Pharmacology and Clinical Sciences, VOL 6, Issue 1, 2017 https://doi.org/10.5530/ijpcs.6.1.1

20. U.S. Food and Drug Administration (2015). Drug Applications for Over-The-Counter (OTC) Drug. Accessed 2014 December 28.

21. World Health Organization (1998). The role of pharmacist in self-care and self-medication. Report of the 4th WHO Consultative Group on the role of pharmacist. Geneva $(\mathrm{CH})$ : WHO; 1998.

22. Zafar, S., Reema, S., Waqar, S., Zubairi AJ, Vaqar T, Shaikh M, Yousaf W, Shahid S, \& Saleem S (2008). Self-Medication amongst University Students of Karachi: prevalence, Knowledge and Attitudes. J Pak Med Association, Student's Corner Original Article, volume 58, No.4 April 2008.https://www.ncbi.nlm.nih.gov/pubmed/18655436 